\title{
Birth of a healthy child after pre-implantation genetic screening of embryos from sperm of a man with nonmosaic Down syndrome
}

\author{
Lusine Aghajanova $^{1}$ • J. M. Popwell ${ }^{2}$ - R. J. Chetkowski ${ }^{3}$ - C. N. Herndon ${ }^{3,4}$
}

Received: 24 February 2016 / Accepted: 26 February 2016 /Published online: 14 March 2016

(C) Springer Science+Business Media New York 2016

In the September 2015 issue, we reported the first case of a healthy life birth from an ICSI-IVF cycle using ejaculated sperm from a man with nonmosaic trisomy 21 with preimplantation genetic screening [1]. At that time, the father's genetic diagnosis was based on his typical phenotype and FISH of peripheral lymphocytes which is limited to chromosomes $13,18,21, \mathrm{X}$ and $\mathrm{Y}$ and provides no information about translocations, deletions, ring chromosomes, etc.

Since the publication of our report, the couple subsequently returned to care seeking a second, female child. At this time, the husband's peripheral blood karyotype, the diagnostic gold standard, was obtained and confirmed the $47, \mathrm{XY},+21$ ( 30 cell count). The finding of nonmosaic Trisomy 21 by traditional culture and banding adds further significance to the case report. Of note, two euploid 46, XX blastocysts were transferred per the cou- ple's request and the wife's serum hCGs indicate an early evolving pregnancy.

Sincerely,

The Authors

Compliance with ethical standards

Conflict of interest The authors declare that they have no conflict of interest.

\section{Reference}

1. Aghajanova L, Popwell JM, Chetkowski RJ, Herndon CN. Birth of a healthy child after preimplantation genetic screening of embryos from sperm of a man with non-mosaic Down syndrome. J Assist Reprod Genet. 2015;32(9):1409-13. doi:10.1007/s10815-015-0525-z.

Lusine Aghajanova

Lusine.Aghajanova@ucsf.edu

1 Department of Obstetrics, Gynecology and Reproductive Sciences, University of California San Francisco, 550 16th Street, 7th Floor, Box 0132, San Francisco, CA 94158, USA

2 Pacific Fertility Center, San Francisco, CA, USA

3 Alta Bates IVF Program, Berkeley, CA, USA

4 Highland Hospital, Alameda County Medical Center, Oakland, CA, USA 